\title{
DECRETO 8.163/2013 E SUAS CONTRIBUIÇÕES PARA O COOPERATIVISMO SOLIDÁRIO COMO ALTERNATIVA PARAA SUPERAÇÃO DAS MIGRAÇÕES FEMININAS NOS ASSENTAMENTOS RURAIS DA REGIÃO DO SISAL
}

\author{
Losângela da Cunha Araújo ${ }^{1}$ \\ Leonardo Magalhães Araújo ${ }^{2}$
}

\begin{abstract}
RESUMO
Este trabalho se propõe a fazer uma análise sobre o decreto $8.163 / 2013$, que institui o Programa Nacional de Apoio ao Associativismo e Cooperativismo no Brasil, como instrumento de organização, desenvolvimento social e sustentabilidade, praticados pelas famílias residentes nos Assentamentos de Reforma Agrária no Território do Sisal no semiárido da Bahia, abordando o empoderamento da mulher assentada através da economia solidária. O cooperativismo tem contribuído para uma dinâmica sustentável em comunidades tradicionais, diminuindo o êxodo e as migrações nestes contextos agrários. O meio rural da região sisaleira é marcado pela concentração fundiária e pela ausência de chuvas. Muitos agricultores/as sobrevivem em pequenas propriedades e desenvolvem estratégias direcionadas para a produção e comercialização de produtos derivados da agricultura familiar através do cooperativismo para sobreviverem. Até meados da década de 1990 as migrações eram frequentes, principalmente entre jovens mulheres rurais, pois, a seca tinha como consequência a vulnerabilidade social desses sujeitos. A falta de oportunidades no campo e a ausência de projetos profissionais no meio rural influenciaram muitas mulheres assentadas do Território do Sisal a buscarem meios de sobrevivência nos centros urbanos e em outras regiões como no Sudeste do Brasil. Dessa forma, são várias as questões sociais e desigualdades causadas pela escassez de chuva no semiárido da Bahia que resultaram na organização das mulheres assentadas através de movimentos sociais e cooperativas. Assim, este trabalho é resultado de um estudo qualitativo e bibliográfico que busca compreender como se deu o processo de empoderamento socioeconômico das mulheres assentadas na região sisaleira, em meio as várias situações adversas e como esta forma de economia sustentável e cooperativista tornou-se uma fonte de renda que impactou na superação da invisibilidade da mulher no meio rural.
\end{abstract}

Palavras-chave: Decreto n. 8.163/2013. Cooperativismo. Mulher rural. Assentamentos. Agricultura familiar.

\footnotetext{
${ }^{1}$ Graduada em Comunicação Social - Habilitação em Rádio e TV pela Universidade do Estado da Bahia UNEB, Pós-Graduada em Gestão em Serviços Sociais e Políticas Públicas pelo Instituto de Educação Pró Saber, Mestranda no Curso de Ciências Sociais: Cultura, desigualdade e desenvolvimento na Universidade Federal do Recôncavo da Bahia. E-mail: losangelavalente@yahoo.com.br.

${ }^{2}$ Graduado em Letras - Habilitação em Língua Inglesa e Portuguesa pela UNEB - Universidade do Estado da Bahia, Pós-graduado em Educação à Distância pela UNEB, Graduando em Direito pela UEFS Universidade Estadual de Feira de Santana. E-mail: leonnardomarujo@gmail.com.
} 


\section{INTRODUÇÃO}

As questões agrárias no Brasil estão relacionadas com a concentração de terras e do domínio das classes homogêneas que sempre excluiu a população subalterna do acesso à propriedade rural de subsistência. $\mathrm{O}$ contexto rural brasileiro é marcado por inúmeros conflitos, consequência da luta do Movimento dos Trabalhadores Rurais Sem Terra - MST pela posse da pequena propriedade no campo. O MST é um movimento social que além da reforma agrária também busca a garantia de políticas públicas de desenvolvimento rural almejando uma sobrevivência digna e o suprimento das necessidades básicas das famílias por meio de movimentos sociais e do cooperativismo.

As organizações de cooperativas solidárias fortaleceram-se como estratégias de meios de sobrevivência coletiva nos assentamentos rurais do Brasil. A mobilização popular em associações e cooperativas ocorreu principalmente após a reestruturação produtiva na década de 1990, (BOGUS, 1994) destaca que as transformações no mundo do trabalho resultaram na redução do emprego principalmente no espaço rural, e influenciou nas relações de trabalho expressos pelas altas taxas de desemprego, impactando principalmente as mulheres no campo que passaram a se organizar socialmente em busca pelos seus direitos.

O Cooperativismo Familiar Solidário é ferramenta estratégica para impulsionar a inclusão socioeconômica da população brasileira, em especial a agricultura familiar. Através da organização política social das camadas mais humildes da sociedade poderemos ampliar as oportunidades, o acesso aos mercados e a geração de desenvolvimento local e regional com sustentabilidade e maior participação e controle social. Este cooperativismo traz o novo, o justo e solidário, onde as relações sociais são horizontais (CORREA e MAGRI, p. 8, 2012).

As atividades femininas rurais, principalmente em comunidades tradicionais, além de estarem relacionadas com a assistência aos fillhos, à preparação das refeições, à manutenção da casa, também incluem uma ajuda constante aos seus companheiros no desenvolvimento da agricultura familiar. Porém, durante décadas as mulheres não tinham nenhum reconhecimento do seu trabalho agrícola e suas ações perpassaram invisíveis por muitas décadas. Assim, são vários os preconceitos e discriminações enfrentadas pelas mulheres, consequência da sua condição de gênero. Essas questões foram por muitos anos marcantes, principalmente em comunidades tradicionais, como por exemplo, os 
assentamentos de reforma agrária no país. Sobre as questões da invisibilidade no espaço rural, o Ministério de Desenvolvimento Agrário do Brasil (2006, pp. 52 - 54) aborda que

\begin{abstract}
A dimensão da invisibilidade do trabalho feminino no campo pode ser visualizada, inicialmente, pela proporção de mulheres ocupadas sem remuneração, que é significativamente mais elevado na agropecuária, em comparação com os demais setores da economia. [...] É nesse sentido que pode afirmar que o trabalho da mulher, sobretudo na agropecuária reproduz a invisibilidade que cerca a percepção da sociedade sobre o papel feminino.
\end{abstract}

A diferenciação entre os gêneros acontece por meio de estereótipos, ou seja, através de uma divisão de nomes e categorias baseadas em critérios tais como sexo e associações psicológicas, idealizados pela sociedade. Scoot (1995) continua argumentando que as teorias do patriarcado explicam que as diferenças de gênero também estão relacionadas com outras desigualdades causadas pela submissão da mulher aos homens.

Diante da subalternidade que as mulheres estavam inseridas, os movimentos e organizações sociais por meio do cooperativismo solidário passaram a ser estratégias de luta na busca pela sua autonomia e empoderamento socioeconômico no campo. As organizações sociais são criadas para garantir a possibilidade da população ter acesso a melhores condições de vida e visam o livre associativismo, almejando também conter a expansão da desigualdade, garantindo o acesso a democracia. Mas, é importante destacar que a disparidade social se destaca em regiões pobres do país como no Semiárido.

O Semiárido está situado na região Nordeste do Brasil, e tem como característica marcante a escassez de chuvas. As condições climáticas, assim como a concentração fundiária, por muitas décadas prejudicam a agricultura familiar de subsistência. Em um estudo realizado pela Empresa Brasileira de Pesquisa Agropecuária - EMBRAPA (2007) aponta que a concentração fundiária é predominante nestes contextos, pois, segundo os dados $70 \%$ dos estabelecimentos rurais e comunidades assentadas possuem menos de 10 hectares e ocupam apenas $11 \%$ da área total territorial. Ainda segundo o estudo da EMBRAPA (2007), as grandes propriedades rurais empregam menos de $4 \%$ da população do campo (pequenos agricultores, assentados de reforma agrária), contribuindo ainda mais para o desemprego e para a vulnerabilidade social principalmente de mulheres.

Analisando os assentamentos de reforma agrária do Território do Sisal no semiárido da Bahia, identifica-se que durante a década de 1990, muitas famílias, 
principalmente jovens mulheres, precisaram migrar para outras regiões em consequência da seca, da falta de trabalho, do acesso à educação e de perspectivas de melhorias na sua qualidade de vida.

Segundo Firmo (2010), as mulheres rurais da região do sisal sobreviveram muitas décadas dentro de uma realidade onde a exclusão social, o trabalho duro e mal ou não remunerado está aos poucos sendo superado. Através do seu empoderamento por meio do processo de cooperativismo e economia solidária, registra-se também o aumento do respeito dos companheiros e do fortalecimento do papel social das mulheres rurais no núcleo familiar.

Assim, este trabalho desenvolveu-se através de uma pesquisa qualitativa e bibliográfica, tendo como objetivo compreender quais as contribuições do Decreto $8.163 / 2013$ para o desenvolvimento do cooperativismo solidário das mulheres rurais assentadas no Território do Sisal, e como essa dinâmica econômica sustentável tem impactado no empoderamento e na diminuição da invisibilidade das mulheres nestes espaços.

Dessa forma, no tópico "Questões de Gênero e a invisibilidade da mulher rural" destaca-se o papel inferiorizado e a discriminação que a mulher enfrentou durante muitas décadas nos contextos agrários de comunidades assentadas. Já em “Cooperativismo Social: Decreto 8.163/2013 e Economia Solidária” aborda quais as contribuições deste decreto que legitima o desenvolvimento do cooperativismo, permitindo a comercialização sustentável e o desenvolvimento socioeconômico dos diversos sujeitos rurais através da economia solidária.

No tópico "Migrações: mulheres rurais no Brasil" aborda-se o movimento migratório feminino no espaço agrário, partindo de um olhar principalmente da dinâmica populacional para a região Sudeste, analisando as causas e consequências sociais deste

processo. E por fim, no tópico "Cooperativismo, direitos sociais e empoderamento socioeconômico da mulher rural: um olhar sobre o assentamento de Lagoa dos Bois em Santaluz-BA" destaca-se o processo de autonomia e trabalho das mulheres rurais assentadas através do cooperativismo solidário no Território do Sisal e a permanência das mesmas de forma sustentável em comunidades tradicionais na região.

\section{QUESTÕES DE GÊNERO E A INVISIBILIDADE DA MULHER RURAL}


De acordo com a Unifem (2006), as desigualdades de gênero no meio rural brasileiro estão atreladas às péssimas condições de vida que esta categoria tem enfrentado nesses contextos. Mas, aos poucos, as mulheres do campo se organizaram e na década de 1980, período que se fortaleceu o feminismo no Brasil, foi fundado o Movimento de Mulheres Trabalhadoras Rurais do Rio Grande do Sul - MMTR/RS e o Movimento da Mulher Trabalhadora Rural do Nordeste - MMTR-NE. Esses movimentos lutam contra as desigualdades da mulher e suas ações são desenvolvidas com o apoio dos movimentos sindicais que se expandiram por todo o país.

De acordo com a FAO (2013), a América Latina e Caribe contam com 121 milhões de pessoas no meio rural, que representam $20 \%$ da população total, destes $48 \%$ são mulheres. Destaca-se ainda, que no Brasil as mulheres rurais tem um importante papel na agricultura familiar, segundo o Ministério de Desenvolvimento Agrário - MDA (2014), são mais de 14 milhões de mulheres sobrevivendo dentro do trabalho agrícola. De acordo com o IBGE 2010, 24,8\% dessas mulheres não possuem companheiros e são responsáveis pelo núcleo familiar. 34,1\% delas com 16 anos ou mais que não possuem rendimentos estão no meio rural. A diferença entre a renda das mulheres ocupadas em relação aos homens no meio rural é de $77,7 \%$, ou seja, comprova-se que a maioria não são remuneradas pelo trabalho desenvolvido na agricultura.

A discriminação e a invisibilidade do trabalho da mulher impactaram nos projetos sociais das jovens rurais de forma negativa, pois, mesmo com o desenvolvimento das políticas públicas e com o avanço nas oportunidades de empoderamento através da agricultura familiar, algumas optam por migrar para os centros urbanos ou buscam um projeto profissional longe do trabalho agrícola, almejando melhores condições de vida. Esse fenômeno é claramente visualizado nos dados abaixo ${ }^{3}$.

As construções dos projetos profissionais revelam-se diferenciadas, conforme o sexo dos jovens. Observa-se que os projetos profissionais que apontam para a permanência na agricultura familiar são mais recorrentes entre os homens $(43,7 \%)$ do que entre as mulheres $(26,9 \%)$. Também é indicada por eles a perspectiva de ser autônomo $(10,1 \%)$, principalmente no ramo da construção civil, mecânica e eletroeletrônicos. Entre eles, ainda 7,1\% pretendem seguir profissão com formação superior ligada à agricultura e à pecuária e $6,7 \%$ almejam trabalhar como técnicos agrícolas, profissão não-agrícola. Já, entre as mulheres, o projeto profissional não-agrícola mais frequente é ser professora $(19,4 \%)$. Depois, aparecem as profissões com curso superior na área de saúde

\footnotetext{
${ }^{3}$ Pesquisa desenvolvida através da Tese de Doutorado "A situação da Juventude na Agricultura Familiar", que apresenta os traços distintivos da situação juvenil na agricultura familiar e a construção de seus projetos profissionais no Rio Grande do Sul.
} 
$(9,4 \%)$, com destaque para enfermagem, farmácia e pediatria (WEISHEIMER, 2009, pp. 273-274).

Sabe-se que as jovens que permanecem no campo estão inclinadas a ajudar no plantio e na colheita através da agricultura de subsistência com o objetivo de satisfazer as necessidades da família, algumas não tem o incentivo ou a oportunidade de frequentar a educação formal, assim, tornam-se apenas agricultoras sem o acesso a uma profissão, resultado de uma sequência de gerações de manuseio agrícola, abordada por Chayanov (1981) como um conjunto de produtores resumidos no núcleo familiar, ou seja, a força de trabalho é baseada apenas nos membros da família.

Assim, a família pode ser vista por sua produção econômica agrícola, como um conjunto de produtores e consumidores de subsistência que a mulher também faz parte do processo de produção, mas, sem ser remunerada. (WESHEIMER, 2002, p. 148), também aborda que

\footnotetext{
Neste sentido, o processo de trabalho na agricultura familiar é o meio pelo qual se desenvolve a reprodução das famílias de agricultores, na medida que, ao mesmo tempo, possibilita a subsistência da família e a produção simples de mercadorias, proporciona também, a formação de novas gerações de agricultores. Estas novas gerações são, por sua vez, fundamentais a realização de tal processo de trabalho.
}

A diferença de gênero no espaço rural que reflete na alternação do índice dos projetos profissionais de permanecer na agricultura entre homens e mulheres, esse fator pode ser justificado na afirmação de Brumer (2004), onde destaca que a divisão do trabalho entre homens e mulheres rurais se reproduz na agricultura, pois, o homem é visto como o detentor do saber rural e não cabe à mulher coordenar as atividades relacionadas à agricultura familiar. Assim, percebe-se que a mulher é colocada em uma posição de inferioridade que a faz buscar outras oportunidades, necessitando urgentemente romper com essa realidade.

Carneiro e Teixeira (1995) afirmam que em meio à construção de uma nova identidade da mulher agrícola, a mobilização popular das mesmas pode ser analisada também como uma forma de garantir visibilidade a sua participação na economia familiar por meio da cooperação. A atividade rural das mulheres, sem o devido reconhecimento, refletiu nas lutas sociais pelos seus direitos. (Schefler, p. 16, 2013) ressalta que 
de recursos sob seu controle pessoal, ampliando o poder de decisão sobre seu uso, a perspectiva de transformar as tradicionais estruturas de dominação, influenciando, inclusive, as manifestações de violência presentes nestes contextos. Neste caso, admite-se que a desigualdade econômica entre homens e mulheres se constitui uma das fortes variáveis preditivas da prevalência da violência contra a mulher, visto que respalda, simbolicamente, o sentido de propriedade e de domínio que subjaz às relações de gênero no meio rural.

Entretanto, quando tratamos de mulheres rurais, nos variados contextos, as questões de gênero são semelhantes e é possível visualizar a discriminação e a invisibilidade das mesmas em assentamentos de reforma agrária no Brasil. O conceito de assentamento foi criado no âmbito da implantação das políticas públicas direcionadas para a reforma agrária, com o objetivo de promover uma intervenção fundiária e garantir o acesso a terra por famílias vulneráveis, excluídas no meio rural e para amenizar os conflitos no campo. De forma gradativa, um dos aspectos fundamentais no processo de Reforma Agrária no país tem sido a relação entre a execução das políticas agrárias e a emergência de mudanças. Na prática, a reforma agrária é marcada por conflitos e tensões no meio rural que excluem principalmente as mulheres do acesso a terra.

É importante destacar também que algumas teorias marxistas sobre o campesinato direcionavam para o desaparecimento da agricultura de subsistência após o desenvolvimento das relações capitalistas de trabalho, isso agravava ainda mais a situação feminina no campo, pois, não havia nenhum reconhecimento do seu trabalho. Lenin (1985) apontava para a degradação das tradições camponesas dentro do cenário capitalista, mas, é possível identificar que as práticas agrícolas resistiram em países que pregavam o capitalismo e as lutas das mulheres pelos seus direitos também se intensificaram nos espaços rurais.

Dentro da perspectiva marxista as relações sociais e as categorias agrícolas eram abordadas mostrando que determinadas formas de produção agrária são incorporadas através da divisão do trabalho, porém, características tradicionais passaram a ser adaptadas aos novos modos de produzir dentro da agricultura familiar através da cooperação, da produção para a própria subsistência e principalmente para uma economia sustentável das mulheres rurais que foram durante décadas invisibilizadas.

\section{COOPERATIVISMO SOCIAL: DECRETO 8.163/2013 E ECONOMIA SOLIDÁRIA}


O cooperativismo e a economia solidária no meio rural passaram a se desenvolver no Brasil como uma estratégia de sobrevivência em meio ao aumento do desemprego e da expansão capitalista contemporânea. Nas últimas décadas, principalmente nos anos 1990 identificam-se, no contexto social brasileiro, vários embates da sociedade civil frente à crise e ao desemprego estrutural, é nesse terreno que nascem as experiências de economia solidária e cooperativistas na agricultura familiar.

MARX (1996), em sua obra “O Capital” ressalta as relações entre diferentes sujeitos no meio de produção capitalista, abordando a produção, a distribuição e o consumo dos bens materiais necessários à sua subsistência, relacionando com a forma que os indivíduos assumem as relações sociais de produção, em meio a um estado histórico de desenvolvimento das forças produtivas que são baseadas na exploração e alienação do trabalhador.

O capitalismo estudado por Marx desenvolve vários processos de reestruturação que resulta no desemprego e na demissão das classes trabalhadoras. $O$ trabalho dentro do capitalismo é precarizado, tratado como mercadoria sem considerar os direitos sociais dos sujeitos já que o lucro é o principal objetivo das relações de trabalho.

A utilização da força de trabalho é o próprio trabalho. O comprador da força de trabalho a consome ao fazer trabalhar o vendedor dela. O último torna-se, desse modo, força de trabalho realmente ativa, o que antes era apenas potentia. Para representar seu trabalho em mercadorias, ele tem de representá-lo, sobretudo, em valores de uso, em coisas que sirvam para satisfazer a necessidades de alguma espécie. É, portanto, um valor de uso particular, um artigo determinado, que o capitalista faz o trabalhador produzir. A produção de valores de uso ou bens não muda sua natureza geral por se realizar para o capitalista e sob seu controle (MARX, p. 297, 1996).

Resultante do processo capitalista, ocorreu a promoção de diversas políticas de ajustes econômicos. Desde 1990 com a adoção do receituário neoliberal no Brasil aprofundou-se o quadro de estagnação da renda per capita acompanhado pela desaceleração na abertura de novas vagas assalariadas formais, acelerando a elevação do desemprego e de postos de trabalho precários que também impactou negativamente no meio rural. Assim, CORREA e MAGRI (2012) destacam que é neste cenário de exploração que a população começa a desenvolver o cooperativismo e a economia solidária como uma alternativa a exploração capitalista principalmente em comunidades rurais subalternizadas.

CORREA e MAGRI (2012) também abordam que a economia solidária pode ser definida como uma forma inovada de produzir, vender, comprar e trocar resultando 
na autonomia social e financeira de famílias que sempre foram excluídas da sociedade. A economia sustentável se desenvolve principalmente através de grupos sociais reunidos por meio do cooperativismo no espaço rural, sem exploração, através de redes de produção e comercialização que fortalecem o grupo que se firmou principalmente na década de 1990 no Brasil.

\begin{abstract}
A segunda metade dos anos 90 marca para a agricultura brasileira um momento de ruptura. [...] O crescimento e a diversificação de representações passam a ter os movimentos sociais e faz com que o leque de demandas também se ampliasse. Algumas destas incluíam a reivindicação de políticas especificas para um público que passava a ser reconhecido como sob uma nova denominação de agricultores familiares, que historicamente foram fragilizados e discriminados na conjuntura de crise (CORREA, MAGRI, p. 109, 2012).
\end{abstract}

Percebe-se que em meio ao grande índice de desigualdade social provocada pelo capitalismo desenvolvem-se novos espaços e modos de produção distintos da economia capitalista. Assim, observa-se também na obra de CORREA e MAGRI (2012) que a partir de 2002 com a implantação de novas políticas públicas governamentais direcionadas para a agricultura familiar em resposta ao agravamento da miséria no campo, os agricultores/as familiares se uniram através do cooperativismo e passaram a desenvolver a economia solidária como um meio de sobrevivência, mas, sem nenhuma legislação que normatizasse esse processo.

Entretanto, em 20 de dezembro de 2013 foi instituído o Decreto 8.163/2013 que visa regulamentar o Programa Nacional de Apoio ao Associativismo e Cooperativismo Social no Brasil contribuindo imensamente para a legitimação da organização social e do desenvolvimento econômico por meio da comercialização de produtos rurais. Este decreto destaca o conceito de cooperativas que tem como objetivo promover o desenvolvimento social de pessoas marginalizadas, apontando os empreendimentos econômicos solidários como organizações de caráter associativo, com gestão democrática.

Os princípios do Decreto 8.163/2013 baseiam-se principalmente no:

Respeito à dignidade e independência da pessoa, inclusive a autonomia individual e coletiva; não discriminação e promoção de igualdade de oportunidades; participação e inclusão de pessoas em desvantagem na sociedade e respeito pela diferença como parte da diversidade humana; geração de trabalho e renda a partir da organização do trabalho com foco na autonomia e autogestão; articulação e integração de políticas públicas para a promoção do desenvolvimento local e regional e na coordenação de ações dos órgãos que desenvolvem políticas de geração de trabalho e renda para as pessoas em desvantagem. 
Assim, o cooperativismo e a economia solidária tornaram-se uma oportunidade de geração de emprego e renda para os diversos sujeitos no campo, principalmente para as mulheres. Muitas jovens que precisavam se deslocar para outras regiões em busca de trabalho passaram a ter oportunidades dentro das próprias comunidades rurais, conquistando aos poucos o seu empoderamento e superando a necessidade de migrar em busca de sobrevivência.

\section{MIGRAÇÕES: MULHERES RURAIS NO BRASIL}

O movimento migratório pode ser definido como as diversas formas de deslocamento praticado pela população entre regiões. A dinâmica das migrações está relacionada com várias causas, na maioria das vezes resultam de questões sociais e principalmente da busca constante por melhorias na qualidade de vida.

Até o final da década de 1920 a economia brasileira era rural, porém, com a queda da República Café com Leite e o início da industrialização a população rural passou a migrar para outras regiões. As migrações no Brasil, segundo BRITO (2009), fazem parte da dinâmica do desenvolvimento da industrialização brasileira. Há uma relação causal entre o excesso de mão de obra que foi excluído nos grandes latifúndios e a necessidade de trabalhadores nos centros urbanos principalmente do Sudeste.

Dentre as principais obras e pesquisas sobre a vida rural e migrações do Nordeste encontra-se "A Caminho da Cidade: a vida rural e a migração para São Paulo" de Eunice Durhan (1984). Segundo Durhan, as migrações acontecem principalmente por questões sociais provocadas pela desigualdade social no campo, entre os homens as migrações para a região Sudeste ocorreram principalmente nas décadas de 1970 e 1980. Esses movimentos são de sujeitos que possuem várias particularidades culturais, a grande maioria vivia em situação de extrema pobreza e pouca escolaridade. As mulheres rurais do semiárido neste período, estavam presas a preconceitos e estereótipos de submissão e seus deslocamentos se fortaleceram precisamente a partir da década de 1990.

Durhan através de uma entrevista concedida a UNICAMP em 2011 destacou que os migrantes rurais eram atraídos para os grandes centros urbanos, exemplo de São Paulo, pela urbanização e na expectativa de superação das condições de pobreza que existia no meio rural. As mulheres nordestinas começaram a migrar na década de $1990 \mathrm{e}$ sonhavam com um bom casamento e com um futuro melhor do que a vida no espaço rural 
do semiárido, mas, a falta de profissionalismo e realidade excludente encontrada nos grandes centros urbanos agravou ainda mais a situação das mulheres migrantes.

As questões sociais que induzem as migrações e transformam os contextos rurais são objetos de estudos essenciais na compreensão de quais as pressões que obrigam a mobilidade espacial das mulheres rurais. Quando abordamos as comunidades tradicionais assentadas, a vulnerabilidade social é ainda mais visível, pois, a falta do acesso a terra e de trabalho no campo colocam os sujeitos rurais em uma posição de exclusão. A categoria "melhorar de vida" está relacionada a um mínimo de estabilidade econômica e quando as migrações ocorrem do meio rural para cidades próximas os sujeitos buscam principalmente o acesso a um emprego.

A mobilidade espacial e ascensão social estão relacionadas com a tradição migratória, pois as mobilidades são utilizadas como recursos de fuga para tensões econômicas e sociais, estando muitas vezes relacionada com tradições comunitárias, sendo um parâmetro universal, tradicional e cultural, na maioria das vezes as mulheres rurais migram para regiões e centros urbanos onde já têm parentes, vizinhos e amigos residindo, pois, sabem que sua condição de gênero reproduz a discriminação e o preconceito.

Os grupos migrantes muitas vezes se organizam e tornam-se um projeto familiar na tentativa de mobilidade social que também pode ser considerada como estratégia contra as questões que envolvem a sociedade que são principalmente sociais e econômicas conforme destaca Durhan.

\footnotetext{
A migração foi explicada como uma tentativa de mobilidade social, isto é, como resposta a problemas criados pela estrutura da sociedade nacional e que são fundamentalmente econômicos. Entretanto, a organização familiar da vida rural leva à colocação do problema da mobilidade em termos da família. Assim, a migração, que aparece como solução para problemas que afetam a família e tendem a ser resolvidos em termos familiares, é um processo condicionado pelo tipo de organização social da sociedade rural (DURHAN, p. 128, 1984).
}

As migrações não são feitas por famílias inteiras, é visível na pesquisa de Durhan que as migrações rurais entre regiões, diferente da mobilidade regional, é feita em grupos pequenos que "arriscam a sorte", assim, o deslocamento do restante da família ocorre de forma gradativa, mas sempre com jovens. Nos grandes centros urbanos, na maioria das vezes, as mulheres ocupam vagas de domésticas. Algumas jovens decidem 
retornar para o Nordeste, mas, não possui condições financeiras e são obrigadas a continuar a sobreviver na exclusão das cidades.

\begin{abstract}
Não se deve esquecer que a sociedade urbana se apresenta, para o camponês em geral, e para o caboclo brasileiro em particular, como os centros dos quais emanam o poder, a autoridade e o saber. A dependência que se encontra em comunidades rurais ante as cidades, que são os centros recreativos, culturais, religiosos, econômicos e políticos na vida nacional, não pode deixar de se manifestar em prestigio dos padrões urbanos em oposições aos rurais (DURHAN, p. 139, 1984).
\end{abstract}

Entretanto, a pesquisa de DURHAN, por outro lado, mostra que os padrões urbanos através da sua sociedade capitalista também se aproveitam da ignorância das mulheres do campo sobre os costumes, cultura e comunicação da cidade. Em um depoimento destaca-se que a mulher rural fica tímida em meio às multidões, teme ser maltratada e humilhada por sua forma de vestir-se e comunicar-se. Assim, o que era para ser uma oportunidade de melhoria na qualidade de vida, contribui ainda mais para as questões de gênero envolvendo mulheres rurais do Nordeste.

A mobilidade espacial analisada por Durhan não estava centralizada apenas nas mobilizações entre regiões, é importante destacar também migrações regionais, territoriais que ocorrem principalmente entre as famílias sem-terra.

Essa mobilidade dos trabalhadores sem terra, frequentemente se restringe ao município ou municípios vizinhos. É importante notar que, estando associada em geral a incorporação maior à economia monetária, ela se dá paralelamente à destruição dos grupos vizinhos com a destruição da autossuficiência econômica. Persistem, entretanto, agrupamentos de parentes e amigos, pois as mudanças de fazenda para fazenda acompanham a direção dos laços pessoais que unem famílias diferentes (DURHAN, p. 121, 1984).

Portanto, essa população sempre foi marginalizada pela elite rural e suas relações migratórias não são centradas apenas em relações familiares, são grupos de vizinhos e sujeitos com uma causa em comum que é a falta de terra para o manejo agrícola, sendo uma grande utopia entre as jovens rurais.

5 COOPERATIVISMO, DIREITOS SOCIAIS E EMPODERAMENTO SOCIOECONÔMICO DA MULHER RURAL: UM OLHAR SOBRE O ASSENTAMENTO DE LAGOA DOS BOIS EM SANTA LUZ/BA 
O assentamento de reforma agrária Lagoa dos Bois está situado no semiárido da Bahia no município de Santaluz do Território do Sisal. Desde a década de 1970 a população rural sem o acesso à terra luta pela posse de pequenas propriedades rurais através da reforma agrária e principalmente lutam contra a elite rural da região. Segundo a ata de fundação do assentamento, em 10 de julho de 1983 foi tomada a posse da Fazenda Lagoa dos Bois com sua emancipação no final da década de 1990 com a posse da terra pelas famílias assentadas.

Constata-se que apenas o acesso a terra não foi suficiente para garantir os direitos sociais dos pequenos núcleos de famílias assentados. Uma vez que, foi durante o governo de Fernando Henrique Cardoso (1995-2002) com a concentração de ações no desenvolvimento capitalista, na reestruturação produtiva e privatizações de empresas públicas no Brasil, que o assentamento de reforma agrária Lagoa dos Bois enfrentou seu período de maior dificuldade e vulnerabilidade social.

Assim, durante a pesquisa constatou-se que $40 \%$ da população jovem na década de 1990 migraram para o sudeste em busca de trabalho, e muitas mulheres estavam nestas estatísticas, $20 \%$ optou pela mobilização espacial dentro do próprio Estado da Bahia, indo para a região metropolitana de Salvador, especificamente para cidade de Camaçari/BA. Ezequiel dos Santos Santiago - líder comunitário no Assentamento de Lagoa dos Bois destaca que

\footnotetext{
De 1989 a 2000 não havia trabalho na região, a população dos assentamentos à exemplo de Lagoa dos Bois, passava várias dificuldades, onde nem trabalho nas grandes propriedades rurais era encontrado, pois, os fazendeiros tinha medo de nós que brigava (sic) por um "pedaço" de terra. O jeito foi "pelejar" (sic) por trabalho em outras regiões ou ver a família passar fome. Até as mulheres buscaram melhores condições de vida em outras regiões.
}

Um fato importante constatado através desta pesquisa é que os pais de família não migravam frequentemente para outros Estados nem para regiões distantes do assentamento, enquanto as jovens mulheres optaram pela mobilidade para a região Sudeste. A falta de opções de trabalho direcionou as famílias que não migraram para trabalhar na colheita do sisal ${ }^{4}$ principalmente no Território de Irecê na Bahia, pois, tinham

\footnotetext{
${ }^{4}$ Sisal é uma planta predominante na região semiárida por ser resistente á aridez e ao sol intenso. No Brasil, os principais produtores são os estados da Paraíba e da Bahia. É também conhecida como agave e utilizase a sua fibra das folhas que, após o beneficiamento, é destinada à indústria de cordas, cordéis, tapetes e atualmente na produção de carros. Os primeiros bulbilhos da planta foram trazidos provavelmente da Flórida, através de uma firma americana. Foi difundido inicialmente no estado da Paraíba e somente no final da década de 30 na Bahia. Atualmente o Brasil é o maior produtor de sisal do mundo e a Bahia é responsável por $80 \%$ da produção da fibra nacional.
} 
medo de perder a pequena propriedade que foi conquistada através da Reforma Agrária. Alguns homens se deslocavam para outro território, porém, deixava a família na pequena propriedade rural, cuidado de pequenas criações de caprinos, ovinos, suínos e aves que eram utilizados para a alimentação do próprio núcleo familiar.

A partir de 2002 como destaca em sua entrevista José Roque Saturnino, presidente da Associação dos Pequenos Agricultores do Assentamento de Lagoa dos Bois - APACOR, a realidade das famílias assentadas foi mudando e melhorando a qualidade de vida da população.

\begin{abstract}
Enfrentamos sim muitas dificuldades, foi preciso força e persistência na luta pelos nossos direitos, já houve muitas situações de desânimo, não víamos esperança de melhorar. Mas, ai a partir de 2002 aos poucos e com as nossas reivindicações junto ao INCRA ${ }^{5}$ começamos a conseguir pequenas linhas de credito, exemplo do $\mathrm{PRONAF}^{6}$, que contribuiu para diminuir o sofrimento do povo de Lagoa dos Bois, ai muitos jovens voltaram para casa, e através do PRONERA $^{7}$ estudaram, alguns são formados Técnicos em Agropecuária, outros Licenciados em Letras Vernáculas e trabalham aqui na região em projetos de desenvolvimento rural financiados pelo governo.
\end{abstract}

De acordo com Maria Baia, griô reconhecida pelo Ministério da Cultura, residente no Assentamento de Lagoa dos Bois, a população passou a viver com menos dificuldades a partir de 2002, a mestre griô destacou as associações e cooperativas que foram criadas com o apoio de políticas públicas governamentais: Associação dos Pequenos Agricultores Familiares de Lagoa dos Bois - APACOR que buscam políticas de desenvolvimento para a comunidade, Grupo de Mulheres Produtoras - GMPR que comercializam produtos derivados da agricultura familiar nas feiras da região, Grupo de Jovens Rurais Caminhando com Cristo que desenvolve ações religiosas e produzem artesanatos para a comercialização.

Patrícia Santiago, assentada e membro do grupo GMPR acrescentou que a participação popular juntamente com o apoio das políticas públicas transformou a realidade das famílias assentadas, destacou que as manifestações culturais também são tradição na comunidade como o grupo de mulheres que cantam "Roda Rosas Vivas",

\footnotetext{
${ }^{5}$ Instituto Nacional de Reforma Agrária.

${ }^{6}$ Programa Nacional de Fortalecimento da Agricultura Familiar que se destina a estimular a geração de renda e melhorar o uso da mão de obra familiar, por meio do financiamento de atividades e serviços rurais desenvolvidos em estabelecimentos rurais.

${ }^{7}$ O Programa Nacional de Educação na Reforma Agrária foi criado para ampliar os níveis de escolarização formal dos trabalhadores rurais assentados. Atua como instrumento de democratização do conhecimento no campo, ao propor e apoiar projetos de educação que utilizam metodologias voltadas para o desenvolvimento das áreas de reforma agrária.
} 
assim como o grupo de jovens "Sabor da Paixão", tornando as mesmas reconhecidas e valorizadas.

Retomando a entrevista de Ezequiel dos Santos Santiago, o mesmo afirmou que é aluno do curso de Direito no PRONERA da Universidade do Estado da Bahia, e destacou que atualmente a comercialização através da economia solidária que ocorre através da união cooperativista no assentamento contribuiu imensamente para a diminuição das migrações dentro da comunidade de Lagoa dos Bois, principalmente de mulheres jovens, conforme destaca-se abaixo no seu depoimento.

\begin{abstract}
Eu que vivo aqui desde a fundação dessa comunidade, acompanhei todo o processo de dificuldades e a transição para a sustentabilidade de Lagoa dos Bois, digo que atualmente que poucas pessoas se deslocam para outras regiões, quando falamos das mulheres esse índice é quase mulo. Não há mais necessidade, é possível viver aqui de forma sustentável. E aqueles que optarem pela migração não é por questões sociais ou dificuldades de sobrevivência, hoje temos qualidade de vida, "estamos no céu" diante de todo sofrimento que já passamos em meio a seca e sem políticas públicas no passado, hoje a gente planta, colhe, alimenta a família e ainda vende, isso é um sonho.
\end{abstract}

De acordo com as entrevistas, atualmente $95 \%$ da população residente em Lagoa dos Bois sobrevivem da agricultura familiar, os poucos que não trabalham na agricultura são jovens, filhos de assentados que trabalham no comércio, como técnicos agropecuários. Destaca-se também que mesmo o curso Técnico em Agropecuária sendo rotulado como um curso para homens, várias jovens de Lagoa dos Bois também estão desenvolvendo essa função que foram capacitadas através do PRONERA.

A produção agrícola produzida pela cooperativa de mulheres da comunidade é comercializada nas feiras locais e regionais. Atualmente as agricultoras, através da associação APACOR, são cadastradas no Programa Nacional de Alimentos - PNAE, que tem como objetivo garantir uma alimentação saudável para os alunos de escola pública através da aquisição de produtos da agricultura familiar, assim vendem a produção agrícola para o poder público local que tem a obrigatoriedade de comprar $30 \%$ da merenda escolar da agricultura familiar.

Percebe-se que pequenos agricultores do assentamento de reforma agrária de Lagoa dos Bois possuem assistência técnica rural através do acompanhamento de projetos de assistência técnica desenvolvido pelo Ministério de Desenvolvimento Agrário - MDA e também são acompanhados pelo Programa Nacional de Segurança Alimentar - PSAN, financiado pela Secretaria de Desenvolvimento Social - SEDES/BA que implantou uma cozinha comunitária para o grupo de produção de mulheres, o que contribuiu 
imensamente para a expansão da comercialização através do cooperativismo e da economia solidária.

Outro fator importante identificado nas entrevistas como essencial no aumento da produção da agricultura familiar é o PRONAF, são beneficiárias do programa mulheres que comprovem seu enquadramento, mediante apresentação da Declaração de Aptidão ao Programa - DAP. O PRONAF é uma linha de crédito que financia a juros baixíssimos e prazos longos, direcionada para pequenos agricultores e vem sendo uma ótima oportunidade de ampliar a produção agrícola, e consequentemente aumenta a comercialização e a renda familiar.

Segundo registros na APACOR, atualmente o Assentamento de Lagoa dos Bois possui 178 famílias, todas sobrevivendo de forma digna através da agricultura familiar, os dados levantados comprovam que o número de famílias naturais do assentamento e que vivem em outras regiões atualmente são insignificantes. Segundo Nilma Santiago, jovem rural de Lagoa dos Bois, "não precisamos mais sofrer pelo mundo, graças a Deus aqui hoje podemos viver junto com nossa família, mesmo em meio à seca do semiárido, pois, temos opções e estratégias para viver dignamente através da agricultura".

\section{CONCLUSÃO}

Assim, através deste estudo é possível concluir que a agricultura familiar por meio do cooperativismo e economia solidária, vem se apresentando nos últimos anos como uma inovadora alternativa de geração de trabalho e renda para as mulheres rurais assentadas no Semiárido da Bahia, tendo como resultado o empoderamento socioeconômico e a valorização das mesmas.

Foi possível perceber também que o êxodo rural de mulheres agricultoras, marcante da década de 1990, foi superado, as jovens assentadas no Território do Sisal estão trabalhando no meio rural com a produção e comercialização de produtos derivados da agricultura familiar. Através dos movimentos sociais, outros direitos também foram alcançados, os quais estão contribuindo para a permanência das mulheres no meio rural, a exemplo do acesso a educação técnica e superior por meio do PRONERA.

Deste modo, ressalta-se que há uma forte presença de várias práticas econômicas e sociais organizadas sobre a forma de cooperativas e associações desenvolvidas por famílias rurais que sempre foram excluídas pela elite rural. A opção 
pelo cooperativismo solidário se deu principalmente na década de 1990 dentro dos assentamentos, a exemplo de Lagoa dos Bois, na tentativa de sobreviver em meio à economia neoliberalista que foi implantada no Brasil e provocou a escassez de trabalho tanto nos centros urbanos como no campo.

Portanto, comprovou-se que os movimentos sociais e o cooperativismo permitem o acesso à democratização de bens e serviços sociais que contribuíram para a diminuição da pobreza e uma sobrevivência sustentável, resultando na autonomia das mulheres rurais. Dessa forma, a agricultura familiar, se apresenta fortalecida mesmo em meio ao capitalismo, permitindo que as diversidades de gênero em comunidades tradicionais convivam de forma pacífica, garantindo que as famílias sobrevivam com dignidade e respeito as diferenças.

\title{
DECREE 8.163/2013 AND ITS CONTRIBUTIONS TO THE SOLIDARY COOPERATIVISM AS AN ALTERNATIVE TO SUPERATION OF WOMEN MIGRATIONS IN THE RURAL SETTLEMENTS OF THE SISAL REGION
}

\author{
Losângela da Cunha Araújo \\ Leonardo Magalhães Araújo
}

\begin{abstract}
This work aims to make an analysis of the Decree 8.163/2013 wich has established the National Program of Support to Associations and Cooperatives in Brazil, as an instrument for social development and sustainability, practiced by families in the Agrarian Reform Settlements in the Sisal Region in the semiarid region of the State of Bahia, addressing the empowerment of woman seated across the solidary economy. The cooperative has contributed to a sustainable dynamic in traditional communities, reducing the exodus and migration in these agrarian contexts. The rural areas of the sisal region are marked by concentration of land and the absence of rain. Many farmers / the surviving people on small farms develop strategies aiming the production and marketing of products derived from family farming through the cooperatives to survive. Until the mid-90s migrations were common, especially among young rural women, because the droughts had resulted in the social vulnerability of those women, because of the povertry. The lack of living opportunities in the countryside and the lack of professional projects in rural areas influenced many women settled in the Sisal region to seek better lifes in urban centres in other regions of the country such as the Southeast of Brazil. Thus, a number of social issues and inequalities caused by the rain shortage in the semiarid region of Bahia that resulted in the organization of women settled through social movements and unions. This paper is the result of a qualitative and bibliographic study that aims to understand how the social and economic empowerment process of women seated in the sisal region happened, amid several adverse situations and how this form of sustainable and cooperative economy has become a source of income that impacted in the overcoming women's invisibility in the countryside.
\end{abstract}


Keywords: Decree 8.163/2013. Cooperatives. Rural women. Settlements. Family agriculture.

\section{REFERÊNCIAS}

BALLARD, T.J, KEPPLE, A.W, CAFIERO , C. The food insecurity experience scale: development of a global standard for monitoring hunger worldwide. Technical Paper. Rome,

FAO , 2013.

BRASIL, Ministério de Desenvolvimento Agrário. Gênero, agricultura familiar e reforma agrária no Mercosul. Ministério de Desenvolvimento Agrário do Brasil. Brasília, 2006.

BRASIL, Ministério de Desenvolvimento Agrário. Mulheres Rurais Brasileiras. Ministério de Desenvolvimento Agrário do Brasil. Brasília, MDA, 2014.

BRITO, F. As migrações internas no Brasil: um ensaio sobre os desafios teóricos recentes. Belo Horizonte: UFMG/Cedeplar, 2009.

BRUMER, Anita e Paulilo, Maria Ignez (organizadoras). As Agricultoras do Sul do Brasil.

REVISTA ESTUDOS FEMINISTAS, DO CFC/CCE/UFSC, VOL. 12, N. 1/2004.

CAMPONESES BRASILEIROS: leituras e interpretações clássicas, organização Clifford Andrew Welch. São Paulo: Editora UNESP; Brasília - DF: Núcleo de Estudos Agrários e Desenvolvimento Rural, 2009.

CARNEIRO, Maria José; e TEIXEIRA, Vanessa L. Mulher rural nos discursos dos mediadores. Estudos Sociedade e Agricultura, 5 novembro 1995.

CHAYANOV, A. La Organización de la unidad económica campesina. Buenos Aires: Ediciones Nueva Visión, 1974.

DESERTIFICAÇÃO E MUDANÇAS CLIMÁTICAS NO SEMIÁRIDO BRASILEIRO / Editores, Ricardo da Cunha Migrações : implicações passadas, presentes e futuras / Paulo Eduardo Teixeira, Antonio Mendes da Costa Braga, Rosana Baeninger (org.). Marília : Oficina Universitária ; São Paulo : Cultura Acadêmica, 2012.

DURHAM, Eunice R. A caminho da cidade: vida rural e a migração para São Paulo. Eunice R. Durhan. São Paulo, Ed. Perspectiva, 1984.

FIRMO, Célia Santos. Desenvolvimento Territorial Sustentável e Gênero: O caso do Território do Sisaleiro na Bahia. Célia Santos Firmo. UFMG, Belo Horizonte - MG, 2010.

FLICK, Uwe. Uma Introdução à Pesquisa Qualitativa. Uwe Flick. 2 ed. Porto Alegre: Bookman, 2004. 
IBGE. Censo demográfico 2010. Brasília, DF, 2011. Disponível em: www.ibge.gov.br/home/estatistica/populacao/censo2010>. Acesso em: 10 de Janeiro de 2016.

LÊNIN, V. L. O desenvolvimento do Capitalismo na Rússia: o processo de formação do mercado interno para a grande indústria. Tradução de José Paulo Netto. São Paulo: Abril Cultural, 1982.

MAGRI, Cledir A. Cooperativismo de credito familiar e solidário: instrumento de desenvolvimento e erradicação da pobreza. Cledir A. Magri, Ciro Eduardo Correa. Passo Fundo, IFIBE, 2012.

MARX, KARL. O Capital. Karl Marx. Volume I. Tradução: Regis Barbosa e Flávio R. Kothe. Nova Cultural. São Paulo. 1996.

MONTAÑO, DURIGUETTO. Carlos, Maria Lúcia. Estado, Classe e Movimento Social. Carlos Montaño, Maria Lúcia Duriguetto. 3 ed. São Paulo: Cortez, 2011.

O progresso das mulheres no Brasil - UNIFEM. Cidadania, Estudo, Pesquisa, Informação e Ação (Cepia). 297 pg. Brasília, 2006.

OLIVEIRA, Marcelo Leles Romarco de Retratos de assentamentos: Um estudo de caso em assentamentos rurais formados por migrantes na região do entorno do Distrito Federal/ Marcelo Leles Romarco de Oliveira. - 2007.

SAYAGO, Doris. Diagnostico Preliminar do Território do Sisal - BA. Doris Sayago. EMBRAPA, DF, 2007.

SCOTT, Joan W. (1986) Gender: A Useful Category of Historical Analysis, American Historical Review, Vol. 91, No 5. Versão brasileira: Gênero: uma categoria útil de análise histórica, Educação e Realidade. Porto Alegre: UFRGS, 1995.

SCHEFLER, Maria de Lourdes N. Gênero, Autonomia Econômica e Empoderamento. O real e o aparente: Sistematização de Processos de Investigação, Ação e/ou de Intervenção Social. Maria de Lourdes Novaes Schefler. Revistas Feminismos. Vol. 1, Salvador, 2013.

WEISHEIMER, Nilson. Os Jovens Agricultores e Seus Projetos Profissionais: Um estudo de Caso no bairro de Escadinhas, Feliz/RS. Dissertação. Mestre em Sociologia. Instituto de Filosofia e Ciências Humanas, Universidade Federal do Rio Grande do Sul, Porto Alegre, 2002.

WEISHEIMER, Nilson. A Situação Juvenil na Agricultura Familiar. Tese. (Doutorado em Sociologia). Instituto de Filosofia e Ciências Humanas, Universidade Federal do Rio Grande do Sul, Porto Alegre, 2009.

WELCH, Clifford Andrew. Camponeses brasileiros: leituras e interpretações clássicas. Clifford Andrew Welch. São Paulo: Editora UNESP, Brasília, DF: Núcleo de Estudos Agrários e Desenvolvimento Rural, 2009.

Disponível em: http://www.ifch.unicamp.br/ojs/index.php/ideias/article/view/476 Entrevista de Eunice Durhan - Acesso em 06 de fevereiro de 2016.

Disponível em: http://www.planalto.gov.br/ccivil_03/2014/2013/Decreto/D8163.htm Acesso em 08 de fevereiro de 2016. 